\title{
Elementos históricos pertencentes ao sistema turístico: avaliação estrutural dos museus localizados na Rota dos Tropeiros - Região dos Campos Gerais (Pr $)^{[1]}$
}

\section{Historical elements pertaining to the touristic system: structural exam of the museums located in the Rota dosTropeiros - Campos Gerais Region (PR)}

\author{
Alessandra Santos dos Santos (SANTOS, A. S.) ${ }^{*}$ \\ Elisiane Dondé Dal Molin (MOLIN, E. D. D.) ${ }^{* *}$
}

\begin{abstract}
RESUMO: O Projeto Rota dos Tropeiros consiste em uma iniciativa de fomento do turismo pelo Estado do Paraná, em conjunto com a Associação dos Municípios dos Campos Gerais, para a promoção turística dos dezesseis municípios que fazem parte da rota. Por meio de uma saída de campo realizada em 2006, foram visitadas as cidades de Lapa, Ponta Grossa, Castro e Tibagi, relacionando-se elementos dos quais o turismo cultural se apropria, destacando-se os museus. Com os dados obtidos por meio de observações estruturadas e pesquisas exploratórias, direcionadas a produção teórica sobre o tema, foram apontados aspectos positivos e negativos comuns aos museus visitados durante a saída. Ao final, com base nas considerações apontadas pelo estudo, formulou-se um diagnóstico geral e sugestões de algumas medidas de correção dos aspectos falhos, visando a otimização estrutural dessas instituições.
\end{abstract}

Palavras-chave: Projeto Rota dos Tropeiros; Turismo Cultural; Museus.

ABSTRACT: The "Rota dos Tropeiros" project consists of an initiative of touristic fomentation by the state of Paraná in association with the "Associação dos Munícipios dos Campos Gerais", to promote tourism in sixteen towns that are part of the "ROTA". By the means of a field work carried in 2006, the cities of Lapa, Ponta Grossa, Castro and Tibagi were visited, relating elements of cultural heritage, with highlight to museums. With data acquired by structured observation and exploratory research directed to theoretical production about the theme, it was pointed common positive and negative aspects of visited museums during each field work. In the end, with basis on considerations indicated by the study, it was formulated a general diagnosis and suggestions of some correcting measures of flawed aspects aiming for structural optimization of those institutions.

Keywords: Rota dos Tropeiros Project; Cultural Tourism; Museums.

\footnotetext{
* Aluna do Programa de Mestrado Acadêmico em Turismo e Hotelaria da UNIVALI - Universidade do Vale do Itajaí - Bolsista do CNPq. Endereço: Rua Firminio Taveira Cruz, no 703 (Apto. 3) - Bairro: Barra - Balneário Camboriú - Santa Catarina - Cep: 88330-050. Telefones: (47) 3363-7175 / (47) 9909-4412. E-mail: alesanto2@yahoo.com.br

** Aluna do Programa de Mestrado Acadêmico em Turismo e Hotelaria da UNIVALI - Universidade do Vale do Itajaí. Bacharel em Gestão do Lazer e Eventos (UNIVALI). Endereço: Rua 3200, nº 60 (Apto. 804) - Bairro: Centro - Balneário Camboriú - Santa Catarina - Cep: 88330-275. Telefones: (47) 32641037 / (47) 9903-8352.E-mail: elisianed@ hotmail.com
} 


\section{INTRODUÇÃO}

Todos os homens fazem parte de uma história, contada diariamente pelo cotidiano através do seu modo de viver e de se relacionar com seus semelhantes. Essa história, apesar de estar viva na memória dos mais antigos, fica contida nas construções e nos objetos que se tornam testemunhas de fatos e realizações ocorridos ao longo do tempo.

Essas construções e objetos são frutos da conexão mantida entre os indivíduos e o meio, os recursos dele extraídos e a tecnologia empregada na transformação destes, que originaram uma série de artefatos e técnicas a ele relacionados.

Considerando estes aspectos, a UNESCO (Organização das Nações Unidas para a Educação, a Ciência e a Cultura), por meio da Recomendação de Paris, de 1972 (consultada em 2006), define o patrimônio cultural como o conjunto de monumentos, grupos de construções arquitetônicas isoladas ou reunidas, e lugares notáveis que sejam de valor universal e excepcional dos pontos de vista da história, da arte, da ciência, da estética, da etnologia e da antropologia.

As preocupações em se preservar o patrimônio cultural no Brasil começaram, conforme Pellegrini Filho (1993), no início do século XX, com iniciativas isoladas. Na década de 1930 o movimento modernista, representado por Mário de Andrade, elaborou um anteprojeto de lei (escrito por ele) visando à preservação dos bens patrimoniais do país, dividindo-os em oito categorias: arte ecológica, arte ameríndia, arte popular, arte histórica, arte erudita nacional, artes aplicadas nacionais e artes aplicadas estrangeiras. Esse texto originou o Decreto-lei 25 de 30 de novembro de 1934, que organizou a SPHAN (Secretaria do Patrimônio Histórico e Artístico Nacional), órgão subordinado ao Ministério da Educação, atualmente denominado como IPHAN (Instituto do Patrimônio Histórico e Artístico Nacional).

Com estas preocupações relacionadas à garantia de preservação, conservação e manutenção do patrimônio cultural, houve o surgimento de um grande interesse voltado ao desenvolvimento do turismo cultural no Brasil, algo que já ocorria no exterior.

Portanto, pode-se definir o turismo cultural como uma prática turística que tem por objetivo, entre outros fins, o conhecimento de monumentos e sítios históricos e artísticos como forma de exercer um efeito positivo sobre estes, contribuindo para a sua 
manutenção e proteção através da geração de benefícios sócio-culturais e econômicos a toda a população local envolvida (INTERNATIONAL COUNCIL ON MONUMENTS AND SITES - ICOMOS, 1976).

Desta forma, através do Programa de Mestrado Stricto Sensu em Turismo e Hotelaria da UNIVALI (Universidade do Vale do Itajaí), realizou-se no mês de outubro uma saída de campo, cujo objetivo central era conhecer os atrativos turísticos e o planejamento que rege um sistema de atrativos integrantes de um produto maior, denominado Rota dos Tropeiros, que envolve dezesseis municípios do Estado do Paraná, sendo os visitados: Lapa, Ponta Grossa, Castro e Tibagi.

A Rota dos Tropeiros consiste em um projeto voltado à projeção das cidades cuja formação se relaciona, historicamente, com o caminho aberto nas matas onde se situa a região sul, da cidade de São Paulo, até Viamão, no Rio Grande do Sul, fomentador do povoamento dos Estados do sul do Brasil, no século XVIII.

Para analisar a oferta turística, fruto da história do tropeirismo e dos aspectos que tangem o turismo e o patrimônio cultural, foi desenvolvido o presente trabalho, que tem como objetivo principal, analisar a estrutura dos museus visitados, traçando um panorama dos aspectos positivos e negativos relacionados à atratividade turística.

Visando o desenvolvimento deste trabalho, foram feitas pesquisas de caráter exploratório, direcionadas ao entendimento dos museus como um aspecto destacável dentro do subsistema cultural, inserido no sistema turístico, do qual fazem parte os elementos histórico-culturais que o turismo cultural dispõe para consolidar suas práticas.

O segundo método de obtenção de dados utilizado foi a observação sistemática estruturada, que teve como base o preenchimento de um instrumento destinado ao registro das informações, previamente elaborado, contendo elementos teóricos relevantes das áreas de turismo e de museus, para possibilitar observações concretas e desprovidas de possíveis viézes.

Pontos positivos e negativos de cada museu foram apontados, resultando em considerações sobre o papel deste perante o cenário turístico e a população local, embasados nos preceitos museológicos e nas condições físicas e estruturais de funcionamento diagnosticadas. 


\section{QUADRO TEÓRICO UTILIZADO PARA A REALIZAÇÃO DO ESTUDO}

A Teoria dos Sistemas, de acordo com a obra clássica de Bertalanffy (1977), consiste no estudo das interações mantidas entre unidades elementares e dependentes, que produzem fenômenos e dinâmicas observáveis em diversos segmentos, servindo de base para a formulação de princípios válidos aos sistemas em geral. Esta mesma teoria pode ser percebida em sistemas abertos, que mantém fluxo contínuo de entradas e saídas pelas relações estabelecidas com o ambiente, ou fechados, quando isolados de seu ambiente externo.

Entretanto, para a sobrevivência e manutenção dos sistemas, torna-se vital as conexões estabelecidas entre seus vários segmentos (CAPRA, 1996). O turismo, visualizado como um sistema aberto, e formado de várias unidades distintas, é uma atividade composta por estruturas atípicas, visualizando-se uma busca teórica incessante voltada à determinação de suas reais dimensões, para auxiliar a racionalização de políticas macroeconômicas destinadas à área, que resultam em uma análise global desse sistema.

Assim, o sistema turístico é formado desses elementos (ecológico, social, econômico e cultural), determinantes de vários modelos destinados a cada uma de suas áreas, que servem para sua análise em causas e efeitos, como meio mais simplificado para o entendimento de suas relações complexas.

No decorrer dos estudos desenvolvidos visando o entendimento do turismo, suas implicações e processos contínuos de transformações e trocas, vários autores, entre eles Molina e Rodríguez (1991), Acerenza (1995) e Hall (2004), aplicaram a teoria dos sistemas para a compreensão científica dos elementos integrantes no processo de planejamento de destinações.

Seguindo a busca pela compreensão do sistema, pode-se citar Beni (1997), que lista uma classificação diferenciada em: subsistema social, subsistema ecológico, subsistema econômico e subsistema cultural. Sendo o subsistema cultural o enfocado para analisar o contexto, este é reconhecido pelo autor como os recursos turísticos oriundos das manifestações culturais que passam a ser disponibilizados para consumo, ao mesmo tempo em que a atividade contribui para a sua preservação. 
Conforme Beni (1997), o turismo cultural é a forma representativa da manifestação dos bens culturais de uma determinada localidade e, para sua maior compreensão, elaborou-se o esquema apresentado na figura 1.
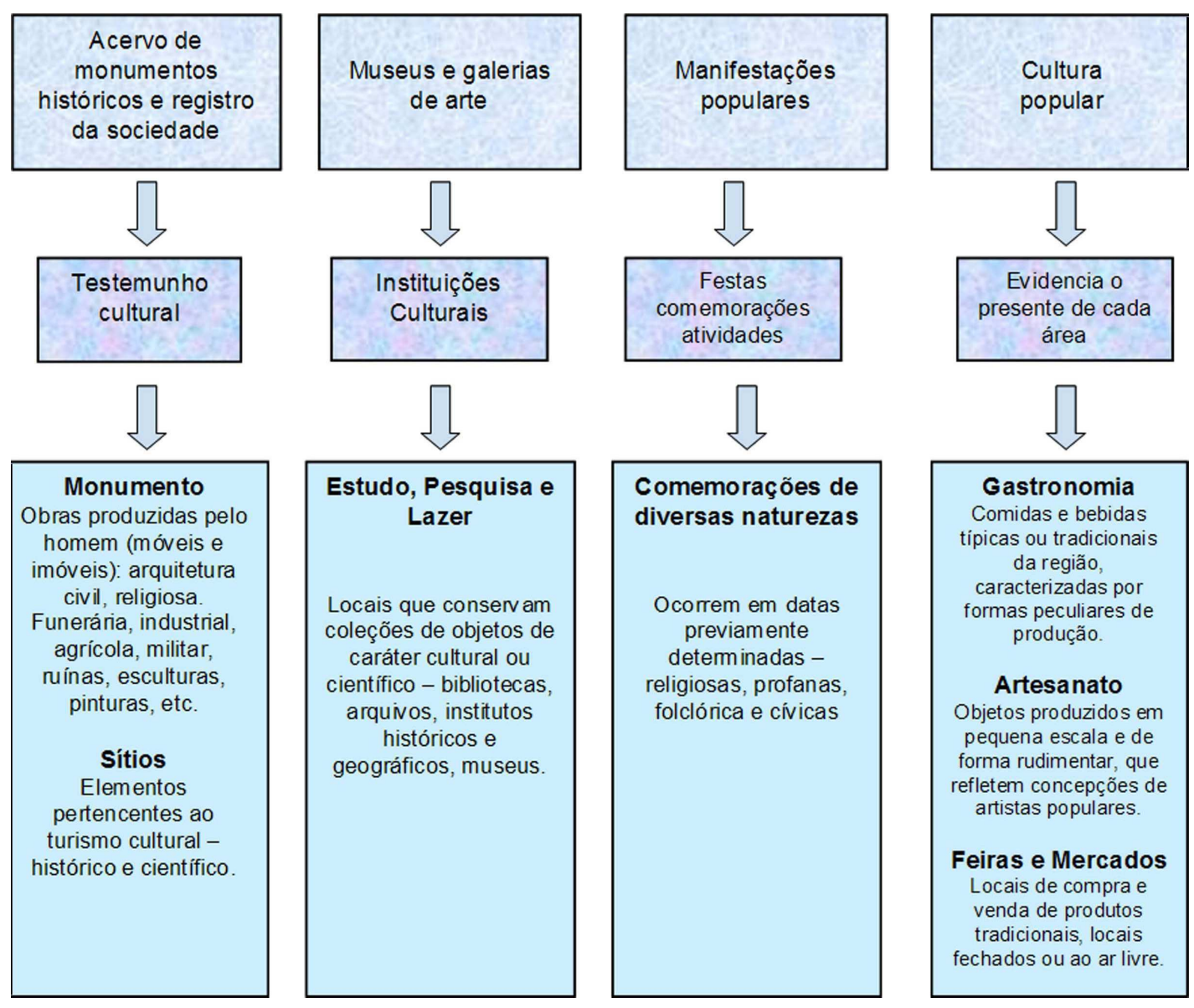

Figura 1: Esquema que retrata a divisão do subsistema cultural

Fonte: Elaborado pelas autoras baseado na obra de Beni (1997)

Com o turismo cultural, de acordo com Pantin (1999) o patrimônio se tornou para a maioria de seus visitantes um objeto de consumo familiar, que proporciona surpresa, relaxamento e prazer, constituindo-se em um bem de fácil acesso, comprovado por um elevado crescimento das ofertas turísticas de cunho cultural.

A valorização da cultura de uma comunidade, um povo ou uma nação, é vital para a sobrevivência e perpetuação desse legado às gerações seguintes, como um retrato dos erros e acertos passados, fundamentais aos sucessos futuros. O retrato ao qual se faz referências, além de referenciais históricos, é composto por objetos móveis e imóveis que constituem os bens culturais. 
Cury (1999) afirma que, dentro do contexto de cultura, os bens culturais adquirem uma "objetividade relativa" porque, devido à condição a qual eles pertencem, ficam inertes no tempo, preservando usos e costumes. Esses bens culturais fazem parte de um conjunto maior, denominado Patrimônio Cultural.

Rússio (1984), entende o Patrimônio Cultural como construção resultante de um processo de atribuição de significados e sentidos, que vai além do avanço das dimensões sociais, usos e interesses a que foi submetido, ou seja, transcende o universo histórico para elementos que demonstram a complexidade e a interação dessas dimensões.

As viagens, conforme Funari e Pinsky (2003), independente da tipologia dos turistas que as realizam, implicam no estabelecimento de contatos humanos e, conseqüentemente, culturais, fomentadas pela troca de experiências entre visitantes e população local, que englobam os costumes e as maneiras de viver de outros povos em realidades distintas.

Nesse sentido, o turismo cultural é aquele voltado a certos tipos de atividades envolvendo visitas a museus e a cidades históricas, em que a interpretação e o conhecimento da importância que seus bens formadores, tangíveis e intangíveis, compõem o patrimônio cultural inserido no universo turístico (PIRES, 2002)

No conjunto dos bens tangíveis, pode-se encontrar uma grande quantidade de objetos produzidos pelo homem que, com o passar do tempo, adquiriram valores e significados, tornando-se destacados como testemunhas materiais da história de uma determinada comunidade, raça ou povo. Suano (1986) salienta que esse "valor agregado" pode ser entendido como "valor cultural" e, por tais características, eles são transportados para dentro do âmbito dos museus.

De acordo com a mesma autora, o museu, como formato institucional, teve sua origem na Grécia Antiga, onde existia o mouseion, mistura de templo e local destinado à pesquisa, voltado para a filosofia, onde todas as obras ali expostas tinham a função de agradar divindades.

O Conselho Internacional de Museus - $\operatorname{ICOM}^{[2]}$ (2001) denomina museus como instituições permanentes, sem fins lucrativos, abertas ao público e a serviço da sociedade que adquirem, conservam, investigam e difundem os testemunhos do homem e seu entorno para a educação e o deleite do público visitante. 
Devido à sua importante abrangência na preservação do legado cultural que identifica uma determinada comunidade, estes podem ser classificados em tipologias, relacionadas por Costa (2004), como: disciplina (arte, ciência, história); espaço geográfico (municipal, estadual, nacional e internacional); administração (pública, privada ou comunitária); temático (vinho, carros, geologia etc.); conteúdo político (guerra, paz) e forma de participação (comunitário, regional, associativo).

O acervo é a essência que mantém vivo um museu, pois, por meio dele, são desenvolvidas pesquisas, tornando-se as informações posteriormente difundidas aos seus visitantes, dimensão em que se destaca seu conceito, estipulado através dos Parâmetros para a Conservação de Acervos do Conselho para Museus, Arquivos e Bibliotecas do Reino Unido, (2004). (CONSELHO PARA MUSEUS, ARQUIVOS E BIBLIOTECAS, 2004) Ele consiste em um conjunto de objetos, cuja guarda é mantida por uma organização colecionadora ou por um colecionador, podendo incluir o próprio edifício ou o local onde se encontra.

As peças que fazem parte de sua composição obedecem a um processo padronizado de musealização que se divide, conforme Santos (2000), na seguinte seqüência: Aquisição (processo em que se adquirem objetos para o acervo); Registro (mecanismo necessário para a identificação do objeto, base para processamento e documentação técnicos); Processamento técnico (catalogação que contém os dados do livro de registros); Processamento fotográfico (reprodução fotográfica do objeto museológico); Inventário (instrumento legal que serve como garantia jurídica de guarda do patrimônio); Pesquisa (coleta de informações que serão posteriormente transferidas ao visitante) e; Marcas de propriedade: (numeração padronizada indicativa da propriedade museológica).

Analisando as conceituações expostas e a importância da pesquisa que o acervo de um museu necessita, ela termina por implicar, principalmente “[...] na manutenção do vínculo com a comunidade, já que é nela que o museu se encontra e onde se processa a cultura [...]”. Pois, assim como o objeto é a linguagem do museu, o homem é o objeto do museu. (SANTOS, 2000, p. 90).

Por isso, é através desse vínculo que se pode obter a valorização dos museus em nível social revertendo, assim, as descobertas obtidas para o senso comum, proporcionando o destaque dos aspectos históricos nele contidos. 
Neste momento visualiza-se a principal função de um museu, que é a manutenção do relacionamento com a comunidade, oferecendo uma oportunidade única para que o indivíduo possa encontrar-se consigo mesmo, identificando-se com os elementos expostos e com a histórica silenciosa contada por eles.

Pires (2002), sob este ponto de vista, ressalta que os museus modificaram-se expressivamente nas últimas décadas, agregando atividades que antes não poderiam ser imaginadas. Essas novas posturas foram implantadas visando integrar a comunidade ao museu, por meio de visitas guiadas, levando-se em conta os interesses dos visitantes, tendo como recursos aulas de pintura, decoração, teatro, exposição de obras de autores da comunidade entre outras. O seu espaço passa a se transformar em ambiente de educação extra-classe, o que contribui para o cumprimento da meta pedagógica, sua principal função.

A promoção de eventos, o intercâmbio entre os acervos de museus distintos e o desenvolvimento de ações pedagógicas, entre outras atividades, neste cenário, se configura para o bom aproveitamento do espaço museológico, proporcionando uma oportunidade de sobreposição das dificuldades técnicas e financeiras que os museus brasileiros possuem.

\section{METODOLOGIA}

A elaboração de um diagnóstico qualitativo, que demonstrasse a situação estrutural e organizacional dos museus em estudo, permeou a decisão de se optar pela observação sistemática e estruturada, no preenchimento de uma ficha de registro comum a todos os museus.

A observação, conforme Vianna (2003) é uma importante fonte de informação em pesquisa qualitativa, constituída por anotações detalhadas que originam seus dados brutos, dependentes da habilidade do observador. "[...] es un procedimiento de recompilación de datos e información que consiste en utilizar los sentidos para observar hechos y realidades sociales presentes y a la gente em el contexto real en donde desarrolla normalmente sus atividades" (ANDER-EGG, 1995, p. 197).

Este mesmo autor classifica os tipos de observação de acordo com os meios utilizados para se observar, o grau de participação do observador, o número de observadores e o local onde ela será realizada. 
Com relação às ferramentas utilizadas, existem duas categorias amplas: a observação estruturada e a não estruturada. A diferença primordial entre essas duas modalidades encontra-se no uso (estruturada) ou não, de um instrumento de coleta de informações, que se configuram em roteiro do que deve ser e o que foi observado, preenchido no ato observatório.

A observação estruturada atendeu aos objetivos da presente pesquisa, focados no diagnóstico dos museus, que considerou as bases conceituais do turismo e da museologia, como meio de prevenir possíveis viézes ocasionados durante as observações.

Para a realização da coleta dos dados referentes aos museus, foi aplicado um modelo de levantamento, que tem como base o processo metodológico de observação, consistindo em uma ficha padrão para o registro de elementos, que se remetem às estruturas físicas e funcionais dos museus pesquisados. Ele foi elaborado com base nos meios metodológicos fundamentais adotados pelos museus, descritos por Santos (2000); pelo sistema formador da infra-estrutura turística de instituições culturais de estudo, pesquisa e lazer/museus, relacionados por Beni (1997), e pelo questionário fechado de preenchimento, elaborado pelo IPHAN (Instituto do Patrimônio Histórico e Artístico Nacional) em conjunto com o MinC (Ministério da Cultura), que compôs, no final do ano de 2006, o Cadastro Nacional de Museus (IPHAN, 2006).

Faziam parte deste formulário questões referentes à localização do museu, descrição do ambiente interno e externo, ao qual se encontrava inserido, acervo, comercialização de objetos, realização de eventos e exposições itinerantes relacionadas às suas temáticas, existência de reserva técnica, formação do corpo de funcionários, quantidade de visitantes registrados no ano de 2005 e procedência dos mesmos.

A complementação das informações disponibilizadas pelo referido instrumento de pesquisa, foi realizada com a descrição dos históricos de formação dos museus e de suas edificações, trabalho este limitado pelo tempo disponibilizado para a visita e para a aplicação da ficha de registro.

\section{A REGIÃO dOS CAMPOS GERAIS (PR) E A ANÁLISE ESTRUTURAL DOS MUSEUS LOCALIZADOS NA ROTA DOS TROPEIROS}

A atividade da tropeada se remonta ao século XVII quando, por ordem da Coroa 
Espanhola, os jesuítas fundaram colônias para a catequização e domesticação dos índios na região sul do Brasil. Com a expulsão dos espanhóis, uma grande quantidade de cabeças de gado e de mulas passou a habitar essas terras em campos abertos e de pastagens abundantes.

Um caminho foi aberto, ligando a Capitania de São Vicente, à região onde hoje está localizada a cidade de Viamão, no Rio Grande do Sul, devido ao número considerável de muares e reses vagando livremente pelos campos provocando, anos mais tarde, a criação de uma feira, denominada Feira de Sorocaba, onde os animais eram comercializados.

O deslocamento de um local para outro demorava aproximadamente um ano, sendo muitos locais escolhidos como ponto de descanso das tropas no decorrer da viagem, sobretudo no inverno, quando o frio rigoroso impedia o seu procedimento. Esses locais recebiam a nomenclatura de Invernada e, geralmente, possuíam a distância de um dia de viagem entre eles. As curtas distâncias deram origem a pequenos povoados ao longo do caminho das tropas, acarretando a formação das cidades que demarcam o mesmo, iniciado no Rio Grande do Sul e findado na Feira de Sorocaba.

No final do século XIX, aproximadamente na década de 1890 , foi realizada a última feira e a atividade deixou de ter a grande projeção do passado, porém, o legado cultural deixado por ela se apresenta até hoje nos hábitos cotidianos que os habitantes das cidades posicionadas no antigo trajeto possuem.

Gemin (2006), ao relatar as relações sociais no âmbito do tropeirismo, afirma que muitos tropeiros, após a doação de sesmarias, começaram a comprar terras ao longo do caminho a preços baixos, formando grandes latifúndios e expandindo a atividade para a região sul. Em torno dessas propriedades e ao longo do percurso, foram constituídas áreas de pouso, onde as tropas se ajudavam no preparo da comida e no trato com os animais.

O convívio entre essas tropas revelava a constituição de uma nova matriz cultural, diferente daquela trazida de Portugal ao Brasil, mas rica em elementos presentes na indumentária, na alimentação, no vocabulário, nos objetos e na lida campeana. 


\subsection{DELIMITAÇÃO GEOGRÁFICA E DESCRIÇÃO DO PRODUTO TURÍSTICO ROTA DOS TROPEIROS}

O Paraná está localizado na parte sul do Brasil, antecedendo Santa Catarina e o Rio Grande do Sul. Há exemplo dessas localidades citadas, o Estado possui uma divisão geo-econômica composta por mesorregiões ${ }^{[3]}$, estipuladas pelo Governo Federal para o agrupamento (em âmbito Estadual) de cidades com características similares entre si, totalizando a configuração em 18 microrregiões.

Para o fomento do turismo no Paraná e o desenvolvimento de roteiros turísticos integrados, essas 18 microrregiões foram agrupadas em 9 regiões principais (segundo o mapa turístico do Estado - 2006), sendo estas: Litoral, Região Metropolitana de Curitiba, Centro Sul, Campos Gerais, Norte, Centro, Sudoeste, Noroeste e Oeste e Municípios Lindeiros. Os Campos Gerais do Paraná, segundo o Dicionário Histórico e Geográfico desenvolvido sobre a região pela UEPG (2008), estão situados na região denominada segundo planalto, englobando as cidades de Arapoti, Campo do Tenente, Cândido de Abreu, Castro, Ipiranga, Jaguariaíva, Ortigueira, Piraí do Sul, Porto Amazonas, Reserva, Telêmaco Borba, Tibagi, Balsa Nova, Campo Largo, Carambeí, Imbau, Ivaí, Lapa, Palmeira, Ponta Grossa, Rio Negro, São José da Boa Vista, Teixeira Soares e Ventania (podendo ser visualizados na figura 2).
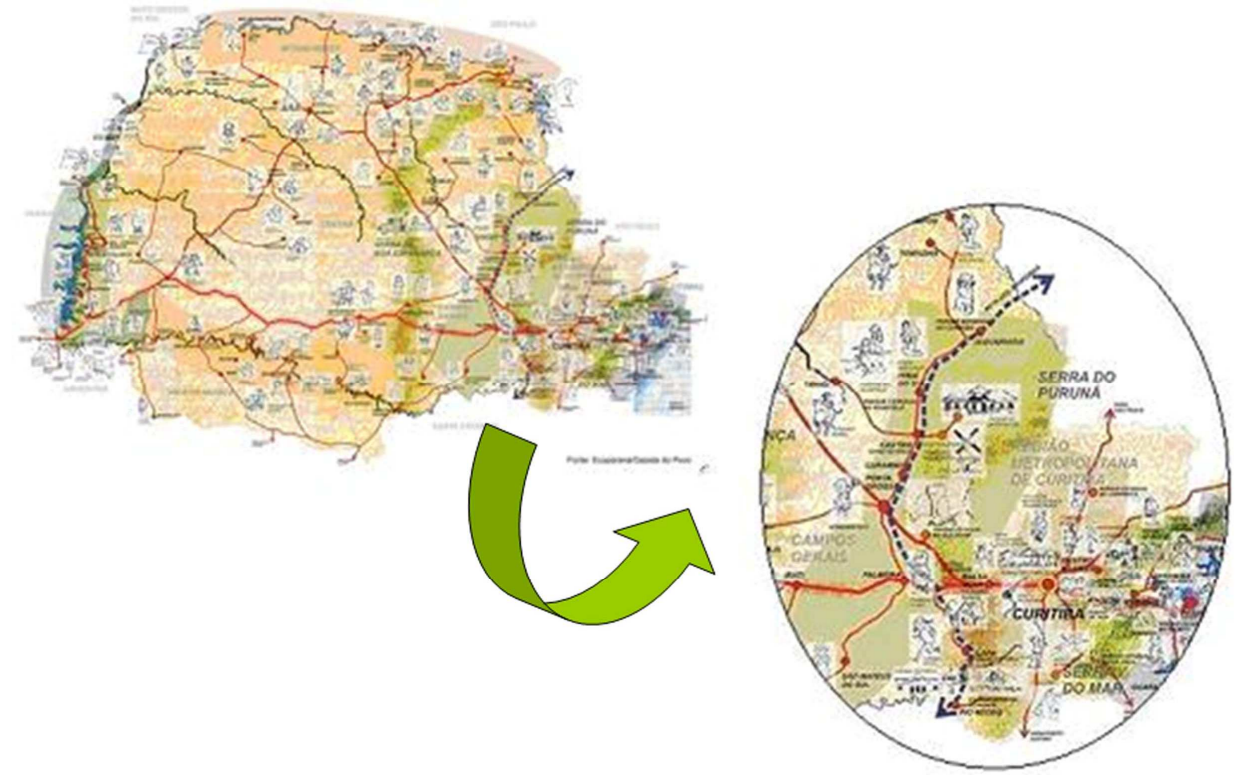

Figura 2: Mapa Turístico do Estado do Paraná, destacando a Região dos Campos Gerais Fonte: Elaborado pelas autoras com base em imagem retirada do site $<$ http://www.pr.gov.br/turismo/images/mapa_turistico.jpg> 
Respeitando esta divisão política e visando a projeção, especificamente, dos Campos Gerais no cenário turístico, por meio de ações sustentáveis fomentadas por políticas direcionadas à área, foi criado o produto turístico "Rota dos Tropeiros" que, de acordo com sua home page (consultada em 2006), visa a composição de uma metodologia para o desenvolvimento sustentável da região, com base no tema do Tropeirismo.

Os objetivos traçados pela Rota dos Tropeiros estão direcionados à formação e consolidação de novos produtos turísticos, atração de turistas, geração de emprego e renda, contribuindo para o desenvolvimento da região.

As estratégias que permeiam a execução do projeto, elaboradas em curto, médio e longo prazo, foram organizadas em três fases: $1^{\text {a }}$ Fase - análise da realidade turística; $2^{\mathrm{a}}$ Fase - avaliação da qualidade e competitividade dos produtos e serviços turísticos; $3^{\mathrm{a}}$ fase - elaboração e implantação e um plano de marketing.

Desde sua criação, fazem parte do projeto "Rota dos Tropeiros" os municípios de Sengés, Arapoti, Jaquariaíva, Tibagi, Piraí do Sul, Telêmaco Borba, Castro, Carambeí, Ponta Grossa, Palmeira, Campo Largo, Porto Amazonas, Balsa Nova, Lapa, Campo do Tenente e Rio Negro. As localizações das cidades integrantes da rota podem ser visualizadas na figura 3.

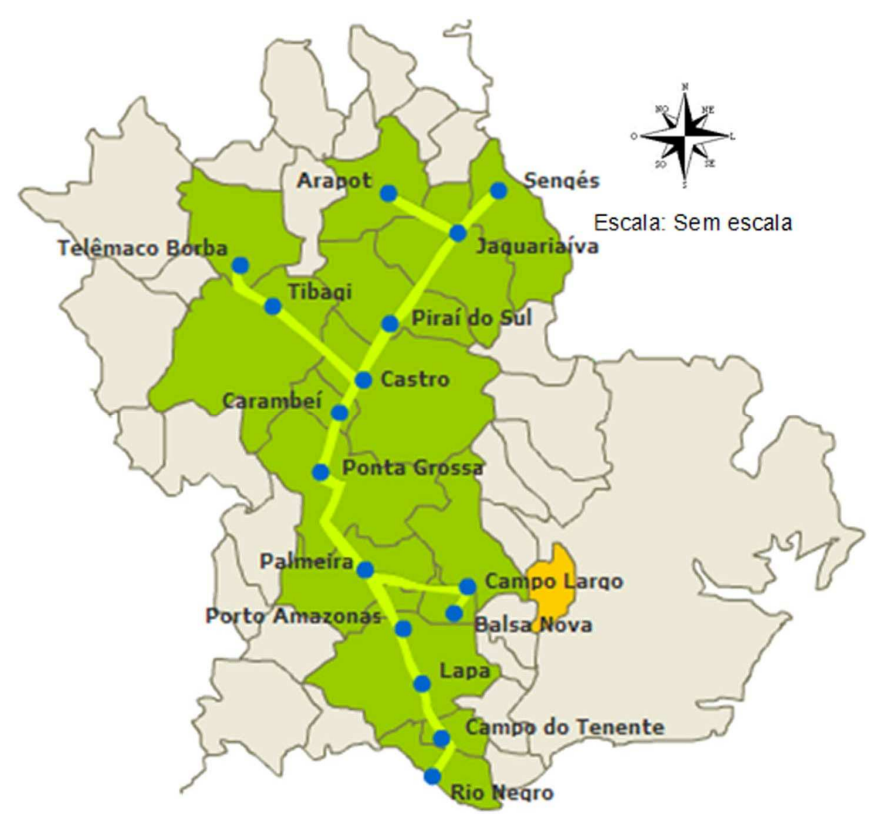

Figura 3: Localização das cidades do produto Rota dos Tropeiros datado de 2006.

Fonte: Retirado do site <http://www.rotadostropeiros.net> 
Até a data em que a saída de campo foi realizada, (Outubro de 2006) a participação no projeto era da Secretaria de Estado do Turismo; Ecoparaná; Paraná Turismo; SEBRAE/PR (Serviço Brasileiro de Apoio às Micro e Pequenas Empresas do Estado do Paraná); Associação dos Municípios dos Campos Gerais; representantes das prefeituras municipais; empresas de iniciativa privada; consultores; técnicos; especialistas e professores.

Além da exploração do principal segmento da região, focado na história e na cultura locais (sobretudo da atividade tropeira), essas cidades dão forma a outros três atrativos turísticos principais: Natureza e aventura (trilhas ecológicas, esportes de aventura, campeonatos de esportes radicais, roteiros ecológicos, observação e contemplação da fauna e da flora e visitas a parques naturais); Fé e misticismo (peregrinações, visitas a igrejas e capelas, participação em eventos e festas religiosas, visitação a locais de reflexão e centros de meditação) e Saúde e bem-estar (clínicas de saúde, Spas e centros de recuperação, relaxamento, centros de estética, beleza e centros gastronômicos).

\subsection{RELAÇÃO DOS MUSEUS ANALISADOS}

Considerando o roteiro previamente elaborado para a realização da saída de campo, foram observados os museus relacionados abaixo:

- Casa de Câmara e Cadeia (Museu de Armas) - Lapa;

- Casa Ney Aminthas de Barros Braga (Museu Ney Barros Braga) - Lapa;

- Centro de Artesanato Aloísio Magalhães (Museu do Tropeiro) - Lapa;

- Museu do Tropeiro - Castro;

- Casa de Sinhara - Castro;

- Museu Histórico de Tibagi Desembargador Edmundo Mercer Jr. - Tibagi.

Das respectivas instituições que participaram da observação de campo, a Casa de Câmara e Cadeia (Museu de Armas), a Casa Ney Aminthas de Barros Braga (Museu Ney Barros Braga), o Centro de Artesanato Aloísio Magalhães (Museu do Tropeiro) e a 
Casa Lacerda, possuem Lei de Proteção Federal. A Casa Lacerda, localizada no município da Lapa, pelo fato de não estar aberta às segundas-feiras, dia em que a visita foi realizada na cidade, não foi inclusa no trabalho desenvolvido.

Na cidade de Ponta Grossa, os trabalhos durante a visita se detiveram nas ações desenvolvidas pela Universidade Estadual de Ponta Grossa (UEPG) com relação ao turismo, não havendo visitas aos atrativos histórico-culturais da cidade.

\subsection{RESULTADOS OBTIDOS COM AS OBSERVAÇÕES EFETUADAS}

Como forma de apresentar os dados coletados durante a visita técnica, realizada nos museus pesquisados, foi relatada a descrição histórica de formação dos mesmos, considerando a edificação e a iniciativa de fundação, como complemento do diagnóstico feito de suas estruturas física e organizacional.

É importante ressaltar que, devido ao pouco tempo disponibilizado para a extração das informações, principalmente as históricas, tais dados foram retirados do material de divulgação do projeto Rota dos Tropeiros, através das home pages das Prefeituras Municipais de Lapa e Castro (2006), e por obras de historiadores locais adquiridas nos municípios visitados.

Pela análise geral dos diagnósticos desenvolvidos com base nos museus visitados, foram detectados aspectos positivos e negativos comuns a todas as instituições. Dentre os aspectos positivos constatados, podem ser relacionados:

- Qualidade do acervo, bastante preservado, quando considerada a idade cronológicas que as peças possuem;

- Receptividade das autoridades e funcionários no ato da coleta de informações;

- Estado de conservação excepcional das edificações que abrigam os museus.

Apesar destes indicadores positivos, após analisar todo o material obtido com a aplicação do instrumento de pesquisa, foram constatados pontos comuns passíveis de correções, que poderiam prolongar a conservação desses bens, uma vez que já estavam passando pelo presente processo. 
A primeira percepção foi a relação mantida entre os objetos museais e o corpo total do acervo, que se configura como uma mistura de grupos de objetos de temáticas diferentes, representando fragmentos históricos, muitas vezes sem a demonstração de suas ligações. Esse preceito, aliado ao fato de que são poucas as atividades promovidas nas estruturas físicas das instituições, e a montagem de exposições permanentes, assemelha a exposição dos objetos a um depósito bem arrumado de artefatos. Por isso, a rotatividade e o trabalho realizados por essas exposições seriam fundamentais na melhora da atratividade dos museus.

Como segunda constatação, foi relacionada à falta de segurança, pois, raramente encontraram-se cordões de isolamento impedindo o acesso aos objetos em exposição, sobretudo a peças pequenas. A qualquer momento, estas poderiam ser tocadas, e o contato com a salinidade do suor das mãos, em longo prazo, poderá comprometer a integridade do objeto. A ausência de um distanciamento pode se apresentar atrativo para pessoas de "má fé", não sendo difícil sair do recinto levando alguma peça, como já ocorreu no Museu do Tropeiro da cidade de Castro, segundo relatos da diretora do mesmo.

A solução apontada para este problema seria, a princípio, o posicionamento estratégico de cordões de isolamento que impeçam os visitantes de tocarem nos elementos em exposição. Com o tempo, poderiam ser confeccionados expositores especiais para a acomodação dos objetos de pequeno porte, garantindo a sua integridade.

$\mathrm{Na}$ parte dos acervos documentais dos museus, incluindo livros, jornais e revistas, estes são consultados livremente, sem o acompanhamento de uma pessoa responsável. Isso significa que, inclusive, por não possuir informações, esse material seja manuseado sem luvas. A presença de um funcionário, inicialmente, seria a garantia e prevenção dessas ocorrências em função de possíveis descuidos.

Nos museus visitados, as esquadrias (janelas e portas) que davam acesso à parte exterior das edificações, encontravam-se abertas, com grande incidência da luz natural nos recintos. Apesar de compreender-se que as mesmas são mantidas nesta posição para não destoarem do contexto representado, a luminosidade constante, aliada à entrada de pó, microorganismos, umidade e calor, com o tempo, comprometerão seriamente as peças, deteriorando cores e materiais com os quais foram concebidos. 
Esse quadro é agravado pela permissão para fotografar os interiores (com exceção do Museu Histórico do Município de Tibagi), em que o flash, mesmo que momentaneamente utilizado, ajuda a acelerar essa degradação progressiva. Para exemplificar, cita-se o exemplo do fluxo de visitantes do Museu de Armas da Lapa que, em 2005, recebeu 13 mil visitantes. Se cada um deles fotografasse apenas uma parte do museu uma única vez sem desligar tal opção, seriam 13 mil flashes de luz sobre uma determinada quantidade de objetos. O efeito acumulativo descrito, a cada ano, ganhará expressividade na medida em que as cores dos objetos começarem a desaparecer.

Contudo, o problema mais relevante detectado foi o despreparo do corpo técnico atuante nos museus visitados. Os funcionários dos museus apresentavam formações diversas, raramente relacionadas às áreas de museologia, história, pedagogia, arquitetura, arqueologia, antropologia e afins. Essa carência de formação profissional, relacionada ao tema, reflete os descuidos com os acervos e o desencontro das informações de cunho histórico passadas ao longo da visita, que se contradiziam em muitos aspectos.

Igualmente, foi identificado o despreparo no recebimento de grupos relativamente grandes de pessoas para o acompanhamento da visita, onde eram dadas, em muitas ocasiões, informações básicas para atender de forma bastante primária as curiosidades do grupo. A não abertura da Casa Lacerda para visitação na saída de campo realizada em Lapa ressalta esta opinião, porque, não foi cogitada uma possível abertura, em caráter especial, para permitir a aplicação do instrumento de coleta de dados.

Quando os funcionários dos museus eram indagados sobre o Cadastro Nacional de Museus, estes alegavam não conhecer o mecanismo e não haver preenchido o formulário de credenciamento. De acordo com as instruções do cadastro, criado pelo Ministério da Cultura em 2006, ao mesmo tempo em que ele servirá para a montagem de um catálogo atualizado contendo todos os museus brasileiros, também é um dos prérequisitos para solicitação de verbas perante os Governos Federal e Estadual, no desenvolvimento de projetos. Os museus não cadastrados perdem este direito, uma vez que, oficialmente, passam a ser inexistentes. 


\section{CONSIDERAÇÕES FINAIS E SUGESTÕES}

A saída de campo realizada para as principais cidades que fazem parte do produto turístico da região dos Campos Gerais do Estado do Paraná, denominado Rota dos Tropeiros, foi uma oportunidade profícua de se conhecer outros contextos e outras realidades turísticas distantes do litoral, em que os elementos histórico-culturais são foco de maior destaque do percurso, evidenciando a prática do turismo cultural.

O turismo cultural, visto sob a perspectiva dos participantes dos roteiros percorridos na viagem realizada, agrega ao patrimônio edificado os elementos imateriais constituído em meio a lutas pela sobrevivência, nas longas viagens realizadas pelos tropeiros, conflitos, guerras e relações sociais mantidas em épocas remotas, que preservaram seus traços no cotidiano das comunidades.

Por estes motivos, é notória a preocupação existente em preservar o patrimônio histórico e cultural nas cidades de Lapa, Tibagi e Castro, onde a coleta dos dados apresentados foi realizada. Isso explica a qualidade, a quantidade e o excelente estado de conservação das construções e das peças formadoras dos acervos dos museus (muitas delas doadas ou emprestadas por membros da comunidade).

A preocupação que o poder público dessas cidades possui em relação à conservação dos bens patrimoniais, foi exposta pela receptividade com que essas autoridades receberam o grupo, e a forma como os atrativos de cada município foram expostos e contextualizados por seus representantes, durante o cumprimento do roteiro turístico, elaborado para a visita técnica.

Com relação à metodologia aplicada para o estudo, baseada em observações sistemáticas guiadas pelo preenchimento da ficha de registros, a mesma se adequou ao propósito do trabalho, na coleta dos dados que foram necessários à elaboração do diagnóstico dos museus pesquisados. Entretanto, o tempo limitado inviabilizou a extração de outras informações, que poderiam vir a complementar a observação realizada como, por exemplo, entrevistas com alguns funcionários dessas instituições.

Voltando-se novamente à análise da realidade pesquisada, para amenizar os aspectos negativos detectados com as observações sistemáticas e sobressair, ainda mais, os pontos positivos demonstrados, como sugestões, foram relacionados alguns itens 
passíveis de execução que poderiam contribuir à melhora da infra-estrutura dos museus, inseridos no Projeto Rota dos Tropeiros:

- Estipular parcerias entre esses museus para o intercâmbio de peças, e a realização de exposições itinerantes, o que fomentaria o desenvolvimento de atividades pedagógicas e a atratividade dos mesmos;

- Realizar cursos e oficinas de capacitação com os funcionários, principalmente os responsáveis pelo acervo e pela recepção do público, para que suas ações possam movimentar engrenagens administrativas e sociais, no intuito de melhor atender aos anseios da população e às entrelinhas do conceito maior de museu;

- Desenvolver pesquisas com o objetivo de conhecer o público visitante, para estimular o retorno destes em outras oportunidades e buscar visitantes potenciais;

- Estimular a produção científica e o resgate histórico do legado do tropeirismo e de suas relações sociais, marcadas no tempo pelo aprofundamento dos dados obtidos com os objetos dos museus, incluindo fotografias, documentos, indumentárias e equipamentos utilizados na atividade;

- Promover outras ações culturais de forma integrada para possibilitar o quadro ideal ao qual um museu deve se moldar: a representação das dinâmicas sociais através do questionamento da realidade.

Sobre esses aspectos sugeridos, destaca-se a qualificação profissional dos funcionários, que poderia ser feita em conjunto com o poder público e as universidades, inseridas nos locais para a contratação de especialistas, sobretudo em museologia, visando o repasse dos princípios básicos que envolvem um museu e o seu acervo.

O dispêndio de recursos necessário à execução dessas ações, mais tarde, conseqüentemente, viria a se converter no incremento da visitação e no destaque ainda maior que a região teria, enfatizando de forma otimizada seus aspectos históricoculturais e a preservação destes. 


\section{REFERÊNCIAS}

ACERENZA, M. A. Administración del turismo: conceptualización y organización. México: Trillas, 1995.

ANDER-EGG, E. Técnicas de investigación social. 24. ed. Buenos Aires: Lúmen, 1995.

BENI, M. C. Análise estrutural do turismo. 8. ed. São Paulo: Editora SENAC, 1997.

BERTALANFFY, L. Teoria geral dos sistemas. 3. ed. Vozes, 1977.

CAPRA, F. C. O ponto de mutação: a ciência, a sociedade e a cultura emergente. 17. ed. São Paulo: Cultrix, 1996.

CONSELHO PARA MUSEUS, ARQUIVOS E BIBLIOTECAS. Parâmetros para a conservação de acervos - um roteiro de auto-avaliação. In: Série Museologia, vol. 5. São Paulo: EDUSP, 2004.

COSTA, H. H. F. G. da. Disciplina de museologia teórica e prática: novas tendências no século XXI. Curso de Especialização em Museologia. UFRGS, $2^{\text {a }}$ Turma, junho de 2004.

CURY, M. X. Exposição: análise metodológica do processo de concepção, montagem e avaliação. São Paulo: FCA/USP, 1999.

FUNARI, P. P.; PINSKY, J. [Org.] Turismo e patrimônio cultural. 3. ed. São Paulo: Contexto, 2003.

HALL, C. M. Planejamento turístico: políticas, processos e relacionamentos. São Paulo: Contexto, 2004.

GEMIN, T de A. Tropeirismo, um legado cultural. Lapa: Grafilapa Gráfica e Editora, 2006.

IBGE. Instituto Brasileiro de Geografia e Estatística. Senso Demográfico 2000 Educação: Resultados da Amostra. Disponível em <http://www.ibge.gov.br/home /estatistica/populacao/censo2000/educacao/censo2000_educ.pdf>. Acesso em 07 mai. 2008.

ICOM. Conselho Internacional de Museus. Código de deontología del ICOM para los museos - 2001. Disponível em <http://www.icom-ce.org/codigo.htm>. Acesso em: 23 mar. 2005.

ICOMOS. International Council on Monuments and Sites. Carta de turismo cultural (1976). Disponível em < http://www.mcu.es/patrimonio/cp/ccr/docs $>$. Acesso em: 08 jun. 2006. 
IPHAN. Instituto do Patrimônio Histórico e Artístico Nacional. Cadastro Nacional de Museus. Disponível em < http://www.iphan.gov.br >. Acesso em: 10 jul. 2006.

MOLINA E., S.; RODRÍGUEZ A., S. Planificación integral del turismo: un enfoque para Latinoamérica. 2. ed. México: Trillas, 1991.

PANTIN, V. Cultura e turismo: rumo a uma economia de mercado. In: O Correio da UNESCO. set./out. 1999 (p. 35-36).

PELLEGRINI FILHO, A. Ecologia, cultura e turismo. Campinas: Papirus, 1993.

PIRES, M. J. Lazer e turismo cultural. 2. ed. Barueri: Manole, 2002.

PREFEITURA MUNICIPAL DA LAPA. História da Lapa. Disponível em <http://www.lapa.pr.gov.br/passeio_histo3.asp>. Acesso em 5 out. 2006.

PREFEITURA MUNICIPAL DE CASTRO. Pontos turísticos. Disponível em: <http://www.castrotur.com.br/pontosturisticos>. Acesso em 5 out. 2006.

ROTA DOS TROPEIROS. Projeto Rota dos Tropeiros. Disponível em <http://www.rotadostropeiros.net>. Acesso em 5 out. 2006.

RÚSSIO, W. Cultura, patrimônio e preservação - Texto III. In: ARANTES, A. A. [Org.] Produzindo o passado: estratégias de construção do patrimônio cultural. São Paulo: Brasiliense, 1984.

SANTOS, F. H. Metodologia aplicada em museus. São Paulo: Mackenzie, 2000.

SUANO, M. O que é museu. São Paulo: Brasiliense, 1986.

UEPG. Universidade Estadual de Ponta Grossa. Dicionário Histórico e Geográfico dos Campos Gerais - Os Campos Gerais do Paraná. Disponível em <http://www.uepg.br/dicion/campos_gerais.htm>. Acesso em 07 mai. 2008.

UNESCO. Organização das Nações Unidas para a Educação, a Ciência e a Cultura. Recomendação de Paris 1972. Convenção sobre a Proteção do Patrimônio Mundial, Cultural e Natural de 16 de novembro de 1972. Disponível em <http://portal.iphan.gov.br/portal/baixaFcdAnexo.do?id=235>. Acesso em 08 jun. 2006.

VIANNA, H. M. Pesquisa em educação: a observação. Brasília: Plano Editora, 2003.

\section{Notas explicativas}

[1] Trabalho apresentado e publicado nos Anais do IV ANPTUR, realizado no período de 27 e 28 de agosto de 2007, na cidade de São Paulo (SP).

[2] Conforme home page oficial do ICOM (Conselho Internacional de Museus), o mesmo consiste em uma organização internacional não-governamental de museus e profissionais de museus. Criado em 1946, 
mantém relações formais com a UNESCO, executando parte de seu programa para museus e desempenhando o papel de consultor no Conselho Econômico e Social da ONU (Organização das Nações Unidas).

[3] Conforme o IBGE (2000), em 1969 O Brasil foi dividido, em âmbito federal, por cinco Grandes Regiões: Norte, Nordeste, Sudeste, Sul e Centro-Oeste, subdivididas em 360 microrregiões homogêneas. Um novo quadro de divisões regionais foi divulgado em 1976, através de mesorregiões homogêneas.

Recebido em: 08 de agosto de 2007

Aprovado em: 08 de setembro de 2007 